\title{
Effect of Pyunkang-tang on Inflammatory Aspects of Chronic Obstructive Pulmonary Disease in a Rat Model
}

\author{
Hyo-Seok Seo ${ }^{1}$, Hyun Jae Lee ${ }^{2}$, and Choong Jae Lee ${ }^{1, *}$ \\ ${ }^{l}$ Department of Pharmacology, School of Medicine, Chungnam National University, Daejeon, Korea \\ ${ }^{2}$ Smith Liberal Arts College and Department of Addiction Science, Graduate School, Sahmyook University, Seoul, Korea
}

\begin{abstract}
We investigated the anti-inflammatory effect of Pyunkang-tang extract (PGT), a complex herbal extract based on traditional Chinese medicine that is used in Korea for controlling diverse pulmonary diseases, on cigarette smoke-induced pulmonary pathology in a rat model of chronic obstructive pulmonary disease (COPD). The constituents of PGT were Lonicerae japonica, Liriope platyphylla, Adenophora triphilla, Xantium strumarinum, Selaginella tamariscina and Rehmannia glutinosa. Rats were exposed by inhalation to a mixture of cigarette smoke extract (CSE) and sulfur dioxide for three weeks to induce COPD-like pulmonary inflammation. PGT was administered orally to rats and pathological changes to the pulmonary system were examined in each group of animals through measurement of tumor necrosis factor- $\alpha$ (TNF- $\alpha$ ) and interleukin-6 (IL-6) levels in bronchoalveolar lavage fluid (BALF) at 21 days post-CSE treatment. The effect of PGT on the hypersecretion of pulmonary mucin in rats was assessed by quantification of the amount of mucus secreted and by examining histopathologic changes in tracheal epithelium. Confluent NCI-H292 cells were pretreated with PGT for $30 \mathrm{~min}$ and then stimulated with CSE plus PMA (phorbol 12-myristate 13-acetate), for $24 \mathrm{~h}$. The MUC5AC mucin gene expression was measured by RT-PCR. Production of MUC5AC mucin protein was measured by ELISA. The results were as follows: (1) PGT inhibited CSE-induced pulmonary inflammation as shown by decreased TNF- $\alpha$ and IL-6 levels in BALF; (2) PGT inhibited the hypersecretion of pulmonary mucin and normalized the increased amount of mucosubstances in goblet cells of the CSE-induced COPD rat model; (3) PGT inhibited CSE-induced MUC5AC mucin production and gene expression in vitro in NCI-H292 cells, a human airway epithelial cell line. These results suggest that PGT might regulate the inflammatory aspects of COPD in a rat model.
\end{abstract}

Keywords - Pyunkang-tang, COPD, inflammation, mucin

\section{Introduction}

Chronic obstructive pulmonary disease (COPD) has been reported to be an important cause of morbidity and mortality and emerged as a typical public health concern worldwide..$^{1-3}$ Recent estimates indicate that the prevalence is approximately ten percent of adults over the age forty. ${ }^{4,5}$ In well-developed countries, cigarette smoking is known to be the most important risk factor for COPD, and exposure to air pollution particles, diverse dusts, and fumes are the additional causative factors. ${ }^{6}$ In underdeveloped nations, exposure to combustion of biomass fuels is in fact a crucial etiological factor of COPD. ${ }^{5}$

Progressive and irreversible obstruction of the airway is

\footnotetext{
*Author for correspondence

Dr. Choong Jae Lee, Department of Pharmacology, School of Medicine, Chungnam National University, 6 Munhwa-Dong, Joong-Gu, Daejeon, Korea.

Tel: +82-42-580-8255; E-mail: LCJ123@cnu.ac.kr
}

the principal pathological characteristic. ${ }^{7}$ Chronic inflammation is in fact the key contributing factor to diminution of pulmonary functionality related to emphysema, chronic bronchitis, and hypersecretion of mucus with the discharge of enzymes which destruct lung cells, proinflammatory mediators, together with reactive oxygen species. ${ }^{8}$ These modifications within the pulmonary system provoke disorders in gas exchange at the pulmonary quantities coupled with respiratory failure. ${ }^{9}$

While the objective of the treatment of COPD is in fact managing symptoms, stopping exacerbation, as well as keeping pulmonary function, ${ }^{10}$ there is no particular and effective pharmacological method. Certainly, the untoward effects of presently used medications for regulating COPD such as corticosteroids urgently suggest the demand for the enhancement of a novel agent to handle the pathophysiology of COPD effectively. ${ }^{11,12}$

Consequently, we suggest that it is very promising to 
Table 1. Composition of PGT

\begin{tabular}{lc}
\hline \hline Herbs & Amounts (g) \\
\hline Lonicerae Flos (Lonicerae japonica Thunberg, Caprofoliaceae) & 4 \\
Liriopis Tuber (Liriope platyphylla Wang et Tang, Liliaceae) & 4 \\
Adenophorae Radix (Adenophora triphilla var. japonoica Hara, Campanulaceae) & 10 \\
Xanthii Fructus (Xantium strumarinum Linne, Compositae) & 10 \\
Selaginellae Herba (Selaginella tamariscina Spring, Selaginellaceae) & 10 \\
Rehmanniae Radix Preparata (Rehmannia glutinosa Liboschitz var. purpurea Making, Scrophulariaceae) & 2 \\
\hline
\end{tabular}

assess the potential activity of traditional herbal medicine for handling the signs of COPD. In Korea, Pyunkang-tang extract (PGT), a traditional herbal preparation in the type of water extract made up of the six medicinal plants (Table 1), continues to be utilized for managing the inflammatory hypersecretion of airway mucus present in COPD, pneumonitis, tonsilitis, as well as pulmonary fibrosis. ${ }^{13}$ Based on this information, it may be suggested that PGT appears to possess a prospective therapeutic effect on inflammatory aspects of pathophysiology of COPD.

To assess the possible effect of particular drugs on COPD, it is vital to make use of an experimental model that is ready to straightforwardly mimic the pathophysiology of human COPD. The majority of COPD models adopted the inhalational exposure to cigarette smoke and yet animal models utilizing biomass fuels, particles of air pollution, together with dusts and fumes have not been developed. ${ }^{14}$ In COPD relating the inhalation of smoke of cigarettes, emphysema, changes in small airway, and inflammation can be observed. ${ }^{15}$ The major pathological features of COPD associated with inhalation of cigarette smoke are hypertrophy of smooth muscle, hyperplasia of goblet cells, inflammatory status alongside the bronchus as well as bronchioles, restructuring of small airway as well as vasculature, and then the outbreak of emphysema. ${ }^{16}$ Additionally, it has been determined that cigarette smoke has over five thousand chemicals. ${ }^{17}$ Among them, two hundred chemicals are in fact very harmful to the human and/or experimental animals. To add, fifty chemicals are known and probable human carcinogens. ${ }^{18}$

Consequently, in this study, we utilized an animal model of COPD-like pulmonary inflammation provoked by simultaneous inhalation of cigarette smoke extract (CSE) as well as sulfur dioxide $\left(\mathrm{SO}_{2}\right)$, a representative air-pollutant generated by combusting biomass fuels. We examined whether PGT significantly manages the inflammatory hypersecretion of pulmonary mucin, the primary biochemical constituent that delivers mucus viscoelasticity, as well as secretion and production of proinflammatory cytokines including tumor necrosis factor- $\alpha$ (TNF- $\alpha$ ) along with interleukin-6 (IL-6), in the present animal model. Furthermore, we assessed whether PGT affects the production of MUC5AC mucin as well as its gene expression induced by CSE in vitro in NCI-H292 cells, a human airway epithelial cell line.

\section{Experimental}

General experimental procedures - All the chemicals and reagents used in this study were obtained from Sigma Aldrich (St. Louis, MO, U.S.A.) unless otherwise specified.

Preparation of PGT - PGT is a preparation consisting of a water extract of six herbs (Table 1). The six herbs were purchased from Dae-won-dang Oriental Drug Store (Seoul, Korea) and identified by emeritus professor of Herbology, Chang Soo Yook (College of Pharmacy, Kyung Hee University, Seoul, Korea). The voucher specimens were deposited at the Herbarium of the College of Pharmacy, Kyung Hee University, Seoul, Korea: Lonicerae Flos (Lonicerae japonica Thunberg, Caprofoliaceae), KHUOPS 2013-75; Liriopis Tuber (Liriope platyphylla Wang et Tang, Liliaceae), KHUOPS 2013-76; Adenophorae Radix (Adenophora triphilla var. japonoica Hara, Campanulaceae), KHUOPS 2013-77; Xanthii Fructus (Xantium strumarinum Linne, Compositae), KHUOPS 2013-78; Selaginellae Herba (Selaginella tamariscina Spring, Selaginellaceae), KHUOPS 2013-79; Rehmanniae Radix Preparata (Rehmannia glutinosa Liboschitz var. purpurea Making, Scrophulariaceae), KHUOPS 2013-80. The six herbs were soaked with $500 \mathrm{~mL}$ of double-distilled deionized water and decocted for $150 \mathrm{~min}$ at $100^{\circ} \mathrm{C}$. The extract was filtered through sterile gauze, concentrated in a rotary vacuum evaporator and lyophilized. One gram of PGT was prepared from $65 \mathrm{~g}$ of mixture of the six herbs (yield: 1.5\%) and stored at $-70{ }^{\circ} \mathrm{C}$ until assayed for its biological activity.

Preparation of CSE Solution - The preparation of CSE Solution was altered from the method reported by $\mathrm{Su}$ and colleagues. ${ }^{19}$ In brief, commercial cigarettes (Marlboro, Philip Morris, Inc., Richmond, VA) were used and cigarette smoke was generated constantly and pulled 
through $100 \mathrm{ml}$ of phosphate-buffered saline (PBS) that was prewarmed to $37^{\circ} \mathrm{C}$ by application of a vacuum to the flask containing the PBS. Each cigarette was smoked for five minutes, and forty cigarettes were used per 100 $\mathrm{ml}$ of PBS to generate a CSE-PBS solution. The solution was then titrated to $\mathrm{pH} 7.0$ - 7.4 and applied immediately after preparation. The concentration of solution used in the present animal study approximately corresponds to human exposure associated with smoking of one pack of cigarettes per day.

Animals - Pathogen-free male Sprague-Dawley (SD) rats (Daehan Biolink, Seoul, Korea), 5 weeks of age weighing 200-220 g, were used. The animals were housed five per cage and were provided with the distilled water and food ad libitum. They were kept under a $12 \mathrm{~h}$ light/ dark cycle (light on 08:00-20:00) at constant temperature $\left(22.5^{\circ} \mathrm{C}\right)$ and humidity $(55 \%)$. Animals were cared for through all of the experimental procedures in accordance with the Guide for the Care and Use of Laboratory Animals regulated by Chungnam National University (the approval number of animal experiment: CNU-00795), Daejeon, Korea.

Experimental design - Thirty rats were randomly assigned to the following six groups: control; CSE plus $\mathrm{SO}_{2}$ exposure; CSE plus $\mathrm{SO}_{2}$ exposure - PGT $157 \mathrm{mg} / \mathrm{kg}$; CSE plus $\mathrm{SO}_{2}$ exposure - PGT $314 \mathrm{mg} / \mathrm{kg}$; CSE plus $\mathrm{SO}_{2}$ exposure-PGT $785 \mathrm{mg} / \mathrm{kg}$; CSE plus $\mathrm{SO}_{2}$ exposuredexamethasone $0.5 \mathrm{mg} / \mathrm{kg}$. Rats were exposed by inhalation to CSE plus $\mathrm{SO}_{2}$ and PGT was administered per os. As a positive control, dexamethasone was administered to rats via intraperitoneal injection. A prepared CSE solution along with $10 \%$ solution of sodium metabisulfite was aerosolized into a Plexiglas exposure chamber, utilizing an ultrasonic humidifier (Samsung Electronics Inc., Seoul, Korea). The concentration of $\mathrm{SO}_{2}$ gas produced by this apparatus was measured to be $150 \mathrm{ppm}$ and the concentration of CSE solution approximately corresponds to human exposure related to smoking of one pack of cigarettes per day. Rats were exposed to CSE plus $\mathrm{SO}_{2}$ for 3 hours per day, 5 days per week, 3 weeks and PGT was administered during the last 2 weeks of treatment. Rats in control group were exposed to fresh air in a similar environment without CSE plus $\mathrm{SO}_{2}$ exposure. All the parameters were examined for all groups.

Histopathologic analysis of tracheal tissues Hematoxylin-eosin and Alcian Blue staining techniques were applied for detecting mucins (stained purple) in tracheal tissues. Formaldehyde-fixed and paraffin-embedded tracheal tissues were cut at $5 \mathrm{~mm}$. Sections were treated with hematoxylin-eosin and the standard Alcian Blue staining method. The Alcian Blue stained mucins blue to purple. ${ }^{20}$

BALF collection and quantitation of in vivo mucins Rats were sacrificed on the last day of experiment and the trachea was cannulated utilizing a sterile polyethylene tube. BAL was performed four times with $5.0 \mathrm{~mL}$ of icecold PBS (pH 7.4) with $80 \%$ of recovery rate. Floating cells and cell debris were taken out by centrifugation of BALF at $12,000 \times \mathrm{g}$ for 5 minutes. The BALF samples were preserved at $-70^{\circ} \mathrm{C}$ until assayed for their mucin contents. The quantity of mucins in each BALF sample was analyzed by using an enzyme-linked immunosorbent assay (ELISA). The BALF samples were prepared with PBS at 1:10 dilution, and $100 \mu \mathrm{L}$ of each sample was incubated at $42{ }^{\circ} \mathrm{C}$ inside a 96-well plate, until dehydrated. Plates were washed three times with PBS and blocked with $2 \%$ bovine serum albumin (BSA) (fraction V) for 1 hour at room temperature. Plates were once again washed three times with PBS and after which incubated with $100 \mu \mathrm{L}$ of 45M1 (NeoMarkers, Fremont, CA, U.S.A.), a mouse monoclonal MUC5AC antibody (1:200), which was diluted with PBS containing $0.05 \%$ Tween 20 and dispensed into each well. After 1 hour, the wells were washed three times with PBS, and $100 \mu \mathrm{L}$ of horseradish peroxidase-goat anti-mouse IgG conjugate $(1: 3,000)$ was dispensed into each well. After 1 hour, plates were washed three times with PBS. Color reaction was developed with 3,3',5,5'-tetramethylbenzidine (TMB) peroxide solution and stopped with $1 \mathrm{~N} \mathrm{H}_{2} \mathrm{SO}_{4}$. Absorbance was read at $450 \mathrm{~nm}$.

Measurements of secretion levels of IL-6 and TNF- $\alpha$ in BALF - The levels of IL- 6 and TNF- $\alpha$ secreted in each BALF sample were measured using an ELISA. The BALF samples were prepared with PBS at a 1:10 dilution, and $100 \mu \mathrm{L}$ of each sample was incubated at $37^{\circ} \mathrm{C}$ in a 96-well plate for $2 \mathrm{~h}$. Plates were washed three times with PBS and blocked with 2\% BSA (fraction V) for $1 \mathrm{~h}$ at room temperature. Plates were again washed three times with PBS and then incubated with $100 \mu \mathrm{L}$ of anti-rat IL-6 or anti-rat TNF- $\alpha$ monoclonal antibody (Santa Cruz Biotechnology, Santa Cruz, CA, U.S.A.) $(1: 1,000)$, which was diluted with PBS containing $0.05 \%$ Tween 20 and dispensed into each well. After $1 \mathrm{~h}$, the wells were washed three times with PBS, and $100 \mu \mathrm{L}$ of horseradish peroxidase-goat anti-mouse IgG conjugate $(1: 3,000)$ was dispensed into each well. After $1 \mathrm{~h}$, plates were washed three times with PBS. Color reaction was progressed with TMB peroxide solution and stopped with $1 \mathrm{~N} \mathrm{H}_{2} \mathrm{SO}_{4}$. Absorbance was read at $450 \mathrm{~nm}$.

NCI-H292 cell culture - NCI-H292 cells, a human 
pulmonary mucoepidermoid carcinoma cell line, were obtained from the American Type Culture Collection (ATCC, Manassas, VA, U.S.A.) and cultured in RPMI 1640 supplemented with $10 \%$ fetal bovine serum (FBS) in the presence of penicillin (100 units $/ \mathrm{mL})$, streptomycin $(100 \mu \mathrm{g} / \mathrm{mL})$ and HEPES $(25 \mathrm{mM})$ at $37^{\circ} \mathrm{C}$ in a humidified, $5 \% \mathrm{CO}_{2} / 95 \%$ air, water-jacketed incubator. For serum deprivation, confluent cells were washed twice with PBS and recultured in RPMI 1640 with $0.2 \%$ FBS for $24 \mathrm{~h}$.

Treatment of cells with PGT - After $24 \mathrm{~h}$ of serum deprivation, cells were pretreated with various concentrations of PGT for $30 \mathrm{~min}$ and treated with $6 \mu \mathrm{L}$ (per 200 $\mu \mathrm{L}$ of culture medium) of CSE solution plus phorbol 12myristate 13-acetate (PMA) $(10 \mathrm{ng} / \mathrm{mL})$ for $24 \mathrm{~h}$ in serumfree RPMI 1640. As a positive control, $20 \mu \mathrm{M}$ of apigenin, a proven compound inhibiting the production of MUC5AC mucin in NCI-H292 cells, was used. PGT and apigenin were dissolved in dimethylsulfoxide and treated in culture medium (final concentrations of dimethylsulfoxide were $0.5 \%)$. Dimethylsulfoxide $(0.5 \%)$ did not affect mucin gene expression or production from NCI-H292 cells. After $24 \mathrm{~h}$, cells were lysed with buffer solution containing $20 \mathrm{mM}$ Tris, $0.5 \%$ NP-40, $250 \mathrm{mM} \mathrm{NaCl}, 3 \mathrm{mM}$ EDTA, $3 \mathrm{mM}$ EGTA, and protease inhibitor cocktail (Roche Diagnostics, IN, U.S.A.), and collected to measure the production of MUC5AC protein (in 24-well culture plate). Total RNA was extracted for determining the expression of the MUC5AC gene (in 6-well culture plate) using RT-PCR.

MUC5AC mucin assay - The amount of MUC5AC mucin protein was determined using an ELISA. Cell lysates were prepared with PBS at 1:10 dilution, and 100 $\mu \mathrm{L}$ of each sample was incubated at $42{ }^{\circ} \mathrm{C}$ in a 96 -well plate, until dehydrated. Plates were washed three times with PBS and blocked with 2\% BSA (fraction V) for $1 \mathrm{~h}$ at room temperature. Plates were again washed three times with PBS and then incubated with $100 \mu \mathrm{L}$ of $45 \mathrm{M} 1$ which was diluted with PBS containing 0.05\% Tween 20 and dispensed into each well. After $1 \mathrm{~h}$, the wells were washed three times with PBS, and $100 \mu \mathrm{L}$ of horseradish peroxidase-goat anti-mouse IgG conjugate $(1: 3,000)$ was dispensed into each well. After $1 \mathrm{~h}$, plates were washed three times with PBS. Color reaction was developed with TMB peroxide solution and stopped with $1 \mathrm{~N} \mathrm{H}_{2} \mathrm{SO}_{4}$. Absorbance was read at $450 \mathrm{~nm}$.

Total RNA isolation and RT-PCR - Total RNA was isolated utilizing the Easy-BLUE Extraction Kit (INTRON Biotechnology, Inc. Kyung-gi-do, Korea) and reverse transcribed by making use of AccuPower RT Premix (BIONEER Corporation, Daejeon, Korea) according to the manufacturer's directions. Two micrograms of total RNA were primed with $1 \mu \mathrm{g}$ of oligo (dT) in a final volume of $50 \mu \mathrm{L}$ (RT reaction). Two microliters of RT reaction product were PCR amplified in a $25 \mu \mathrm{L}$ reaction volume by utilizing Thermorprime Plus DNA Polymerase (ABgene, Rochester, NY, U.S.A.). Primers for MUC5AC were: (forward) 5'-TGA TCA TCC AGC AGG GCT-3' and (reverse) 5'-CCG AGC TCA GAG GAC ATA TGG G-3'. As quantitative controls, primers for Rig/S15 rRNA, which encodes a small ribosomal subunit protein, a housekeeping gene that is constitutively expressed, were used. Primers for Rig/S15 were: (forward) 5'-TTC CGC AAG TTC ACC TAC C-3' and (reverse) 5'-CGG GCC GGC CAT GCT TTA CG-3'. The PCR mixture was denatured at $94{ }^{\circ} \mathrm{C}$ for 2 min followed by 40 cycles at $94^{\circ} \mathrm{C}$ for $30 \mathrm{~s}, 60^{\circ} \mathrm{C}$ for $30 \mathrm{~s}$ and $72{ }^{\circ} \mathrm{C}$ for $45 \mathrm{~s}$. After PCR, $5 \mu \mathrm{L}$ of PCR products were subjected to $1 \%$ agarose gel electrophoresis and visualized with ethidium bromide under a transilluminator.

Statistical analysis - Means of individual groups were converted to percent control and expressed as the mean \pm standard error of the mean (S.E.M.). The differences among groups were analyzed using one-way ANOVA and Newman-Keuls test as a post-hoc test using SigmaStat ver.4.0 (Systat Software, San Jose, CA, U.S.A.). A pvalue $<0.05$ was considered statistically significant.

\section{Results and Discussion}

As above mentioned in the Introduction, it is essential to make use of an experimental model that can closely simulate the pathophysiology of human COPD, in order to carefully examine the potential effect of certain agents on COPD. Human COPD is very progressive over an extended period of time and consists of chronic bronchitis, emphysema, pulmonary hypertension, metaplasia of goblet cells, and remodeling of small airways. However, any established animal model up to now has not accurately reflected all of the attributes of human COPD. Most COPD models have used inhalational exposure to cigarette smoke. Ideal animal models using biomass fuels, particles of air pollution, and dusts and fumes have not been developed yet. ${ }^{14}$ Therefore, in the present study, we used an animal model of COPD-like pulmonary inflammation provoked by inhalation of a mixture of CSE and $\mathrm{SO}_{2}$, an exemplary air-pollutant generated after combustion of biomass fuels.

It has been observed that hypersecretion of airway mucus is in fact on the list of the major symptoms connected with severe pulmonary inflammatory diseases 
including COPD. ${ }^{3}$ There are two methods to cleanse away excessive mucus from the airway. They are the removal of the mucus by way of physical methods and the inhibition of production and secretion of mucus using pharmacological agents. Nevertheless, clinically, the physical method triggers irritation of the airway luminal wall and stimulates hypersecretion of mucus through a reflex mechanism. Therefore, pharmacological methods for controlling production and secretion of mucins, the major biochemical constituent that gives mucus viscoelasticity, have evolved to be a crucial approach for regulating the hypersecretion of airway mucus. While glucocorticoids suppress the hypersecretion of airway mucus, they have several limitations in their application as pharmacotherapies of human diseases involving pulmonary mucus hypersecretion. ${ }^{20}$ An alternative approach for dealing with airway mucus hypersecretion is to regulate excessive mucin secretion by utilizing traditional herbal medicines that have been employed for the management of respiratory inflammatory diseases. Regulation of inflammatory reactions seems to be the action that is the best for treating diverse pulmonary diseases including COPD. While it would be quite hard to achieve this regulation with typical pharmacological agents, traditional herbal medicines might be a unique alternative solution driven by their plural actions to alleviate the various symptoms associated with diverse respiratory inflammatory diseases. ${ }^{21,22}$

Based on this information, in order to examine the possible effects of PGT on a COPD model, we investigated whether, in this animal model, PGT significantly controls the inflammatory hypersecretion of pulmonary mucin, and the production and secretion of proinflammatory cytokines including TNF- $\alpha$ and IL-6 in BALF. Among the twenty-one or possibly more MUC genes encoding human mucins noted up to now, MUC5AC was primarily expressed in goblet cells in airway surface epithelium. Consequently, we examined the effect of PGT on CSE along with PMA-induced MUC5AC mucin gene expression and production in NCI-H292 cells. This is a human pulmonary mucoepidermoid cell line, which are frequently utilized with the aim to elucidate mechanisms involved in airway mucin production and gene expression. ${ }^{21}$ PMA provoked MUC5AC gene expression in NCI-H292 cells. ${ }^{22}$ In the present in vitro experiment, PMA may synergize the action of CSE on MUC5AC mucin production as well as gene expression. As shown in Fig. 1, MUC5AC mucin gene expression induced by CSE plus PMA was inhibited by pretreatment with PGT (Fig. 1). There was no remarkable cytotoxicity in the range of treatment concentrations (data not shown). In addition,

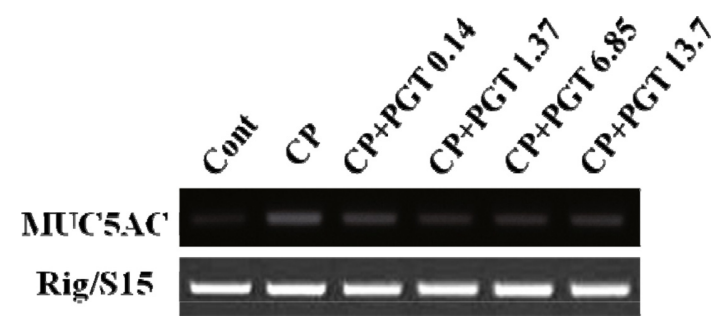

Fig. 1. Effect of PGT on CSE plus PMA-induced MUC5AC mucin gene expression.

NCI-H292 cells were pretreated with various concentrations of PGT for $30 \mathrm{~min}$ and then stimulated with the mixture of cigarette smoke extract and PMA for $24 \mathrm{~h}$. MUC5AC gene expression was measured by RT-PCR. Three independent experiments were performed and the representative data are shown. Cont: control; PGT: Pyunkang-tang extract; CP: the mixture of CSE (cigarette smoke extract) and PMA; PMA: phorbol 12-myristate 13-acetate. Concentration units are $\mu \mathrm{M}$.

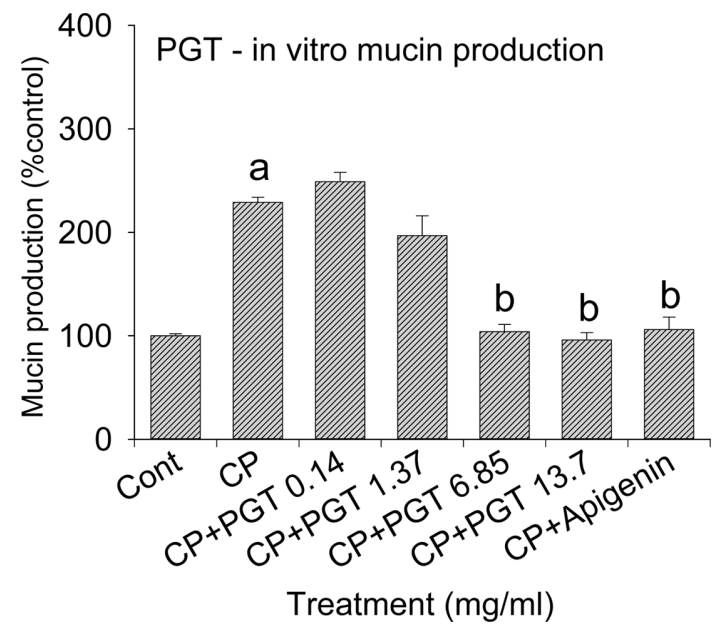

Fig. 2. Effect of PGT on CSE plus PMA-induced MUC5AC mucin production.

NCI-H292 cells were pretreated with various concentrations of PGT for $30 \mathrm{~min}$ and then stimulated with the mixture of cigarette smoke extract and PMA for $24 \mathrm{~h}$. Cell lysates were collected for measurement of MUC5AC mucin production by ELISA. Each bar represents a mean \pm standard error of values obtained from 3 culture wells in comparison with that of the control set at $100 \%$. Three independent experiments were performed and the representative data are shown. Cont: control; PGT: Pyunkangtang extract; CP: the mixture of CSE (cigarette smoke extract) and PMA; PMA: phorbol 12-myristate 13-acetate. Concentration units are $\mu \mathrm{M}$.

a; significantly different from control $(\mathrm{p}<0.05)$.

$b$; significantly different from the mixture of cigarette smoke extract and PMA alone $(\mathrm{p}<0.05)$.

PGT inhibited, dose-dependently, MUC5AC mucin production induced by CSE along with PMA (Fig. 2). The amount of mucin in the cells of CSE plus PMA-treated cultures was $100 \pm 2 \%, 229 \pm 5 \%, 249 \pm 9 \%, 197 \pm 19 \%$, $104 \pm 7 \% 96 \pm 7 \%$ and $106 \pm 12 \%$ for the control, CSE plus PMA only, CSE plus PMA - PGT $0.14 \mathrm{mg} / \mathrm{mL}$, CSE 

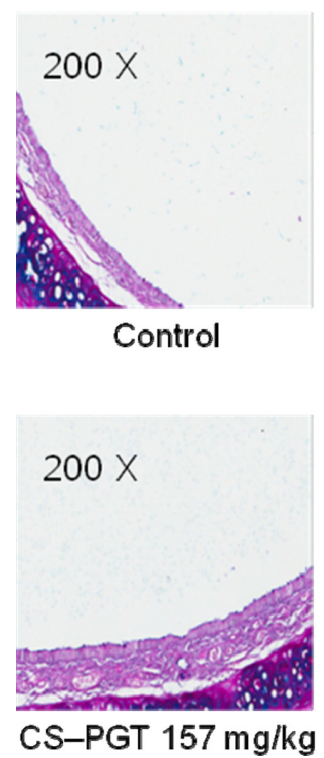
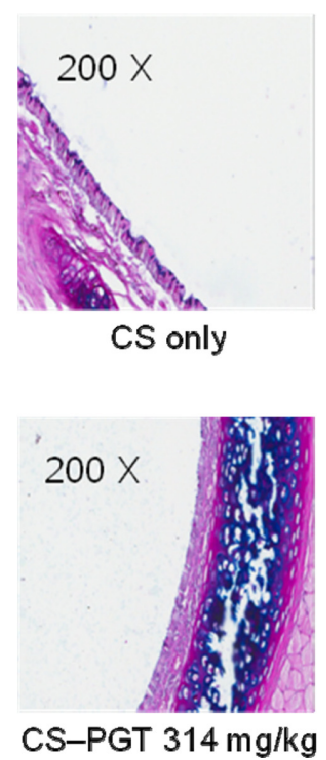

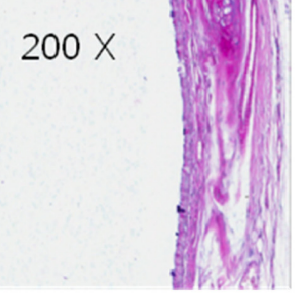

CS-Dexa $0.5 \mathrm{mg} / \mathrm{kg}$

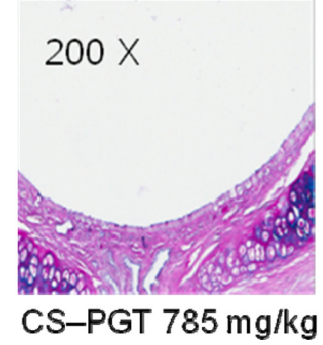

Fig. 3. Effect of PGT on epithelial mucosubstances in trachea of rats exposed to cigarette smoke extract plus sulfur dioxide (Hematoxylin and eosin staining, $200 \mathrm{X}$ ).

Rats were exposed by inhalation to the mixture of cigarette smoke extract and sulfur dioxide and the effect of orally administered PGT on epithelial mucosubstances (stained blue to purple) in the trachea was investigated, as described in the Materials and Methods. The blue to purple staining in luminal surface epithelium indicates mucins. Cont: control; PGT: Pyunkang-tang extract; Dexa: dexamethasone; CS: the mixture of cigarette smoke extract and sulfur dioxide.

plus PMA - PGT $1.37 \mathrm{mg} / \mathrm{mL}$, CSE plus PMA - PGT $6.85 \mathrm{mg} / \mathrm{mL}$, CSE plus PMA - PGT $13.7 \mathrm{mg} / \mathrm{mL}$ and CSE plus PMA - Apigenin $20 \mu \mathrm{M}$ groups, respectively (Fig. 2). These two results indicate that PGT might suppress CSE-induced gene expression and production of MUC5AC, by directly acting on airway epithelial cells.

Additionally, CSE has been described to cause hyperplasia of goblet cells and hypersecretion of pulmonary mucus, in vivo. ${ }^{16}$ Based on this report, we examined whether PGT significantly controls the inflammatory hypersecretion of pulmonary mucin triggered by inhalation of CSE. As shown in Fig. 3 and 4, in this COPD-like inflammation animal model, orally-administered PGT suppressed both the increase of mucosubstances in goblet cells of tracheal tissues and mucin secretion in BALF. Exposure of rats to CSE plus $\mathrm{SO}_{2}$ for 3 weeks resulted in a significant increase in mucosubstances (mucins, stained purple) (Fig. 3) and mucin secretion from tracheal tissues (Fig. 4), compared with that of the control group. However, orally-administered PGT inhibited both the increase of mucosubstances (stained purple) in goblet cells of tracheal tissues and mucin secretion in BALF. The amount of mucin in the BALF samples was $100 \pm 22 \%, 473 \pm 65 \%, 262 \pm 64 \%$, $220 \pm 62 \%, 163 \pm 2 \%$ and $254 \pm 29 \%$ for the control, CSE plus $\mathrm{SO}_{2}$ only, CSE plus $\mathrm{SO}_{2}$ - PGT $157 \mathrm{mg} / \mathrm{kg}$, CSE plus $\mathrm{SO}_{2}$ - PGT $314 \mathrm{mg} / \mathrm{kg}$, CSE plus $\mathrm{SO}_{2}$ - PGT $785 \mathrm{mg} /$

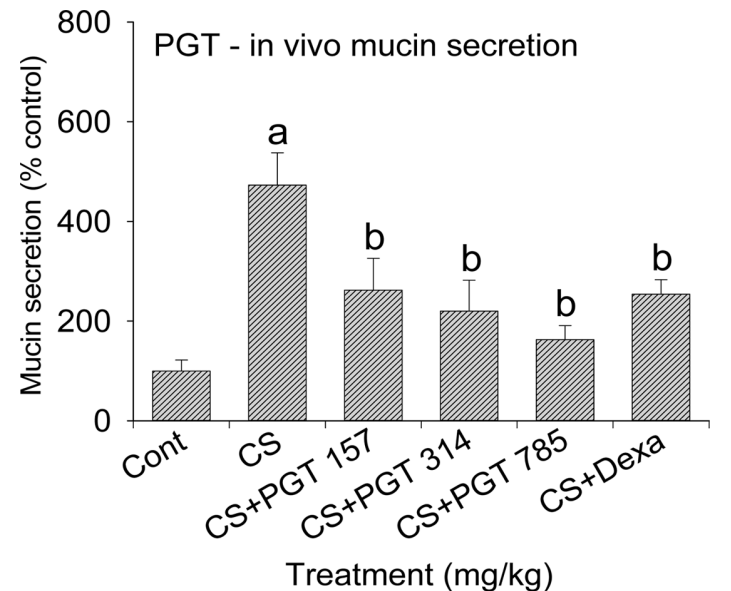

Fig. 4. Effect of PGT on secretion of in vivo airway mucin from rats exposed to cigarette smoke extract plus sulfur dioxide.

Rats were exposed by inhalation to the mixture of cigarette smoke extract and sulfur dioxide and the effect of orally administered PGT on secretion of in vivo airway mucins was investigated, as described in the Materials and Methods. Each bar represents the mean \pm standard error of values obtained from five rats. Cont: control; Dexa: dexamethasone; PGT: Pyunkang-tang extract; CS: the mixture of cigarette smoke extract and sulfur dioxide. Concentration units are $\mathrm{mg} / \mathrm{kg}$.

a; significantly different from control $(\mathrm{p}<0.05)$.

$\mathrm{b}$; significantly different from the mixture of cigarette smoke extract and sulfur dioxide alone $(\mathrm{p}<0.05)$.

$\mathrm{kg}$, and CSE plus $\mathrm{SO}_{2}$ - dexamethasone $0.5 \mathrm{mg} / \mathrm{kg}$ groups, respectively. A positive control, dexamethasone, inhibited 


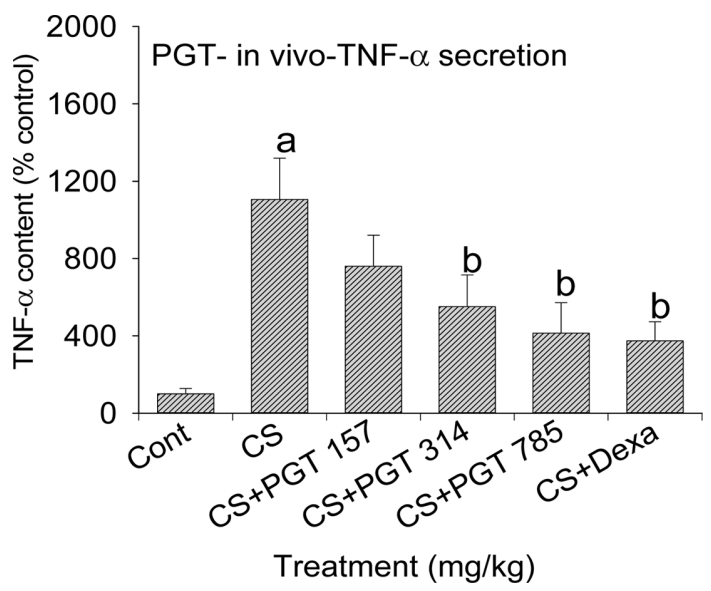

Fig. 5. Effect of PGT on secretion level of TNF- $\alpha$ in BALF from rats exposed to cigarette smoke extract plus sulfur dioxide.

Rats were exposed by inhalation to the mixture of cigarette smoke extract and sulfur dioxide and the effect of orally administered PGT on secretion level of TNF- $\alpha$ in BALF was investigated, as described in the Materials and Methods. Each bar represents the mean \pm standard error of values obtained from five rats. Cont: control; Dexa: dexamethasone; TNF- $\alpha$ : tumor necrosis factor- $\alpha$; BALF: bronchoalveolar lavage fluid; PGT: Pyunkangtang extract; CS: the mixture of cigarette smoke extract and sulfur dioxide. Concentration units are $\mathrm{mg} / \mathrm{kg}$.

$\mathrm{a}$; significantly different from control $(\mathrm{p}<0.05)$.

$\mathrm{b}$; significantly different from the mixture of cigarette smoke extract and sulfur dioxide alone $(\mathrm{p}<0.05)$.

mucin secretion and the increase of mucosubstances in tracheal tissues, due to its anti-inflammatory effects. These outcomes suggest that PGT might control hypersecretion of pulmonary mucus and/or hyperplasia of goblet cells, the two major pathological features in COPD.

IL-6 is a pleiotropic and highly effective proinflammatory cytokine involved in the regulation of the host immune response to infection. When COPD is exacerbated, levels of IL- 6 are increased within the human body. ${ }^{23}$ IL- 6 was reported to be strongly linked to obstruction of airflow in COPD patients. ${ }^{24}$ TNF- $\alpha$ is a common proinflammatory cytokine with pleiotropic effects on host responses to pathogenic microbes and it was described getting overproduced in COPD.$^{25}$ In a previous study, the amount of TNF- $\alpha$ in exhaled breath together with the content of TNF- $\alpha$ in lung tissues were reported to be considerably higher in the COPD group compared with those of the non-COPD. ${ }^{26}$ After inhalational exposure of CSE to the pulmonary system, the quantity of TNF- $\alpha$ and IL-6 increased in the BALF of the model animal. ${ }^{14}$ As can be seen in Fig. 5, exposure of rats to CSE plus $\mathrm{SO}_{2}$ for 3 weeks resulted in a significant increase in the level of $\mathrm{TNF}-\alpha$, a representative proinflammatory cytokine, compared with that observed for the control group. However,

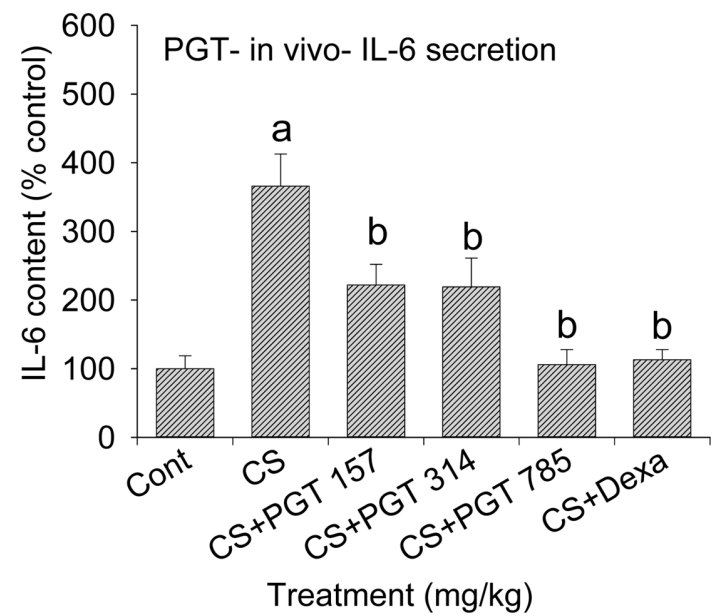

Fig. 6. Effect of PGT on secretion level of IL-6 in BALF from rats exposed to cigarette smoke extract plus sulfur dioxide.

Rats were exposed by inhalation to the mixture of cigarette smoke extract and sulfur dioxide and the effect of orally administered PGT on secretion level of IL-6 in BALF was investigated, as described in the Materials and Methods. Each bar represents the mean \pm standard error of values obtained from five rats. Cont: control; Dexa: dexamethasone; IL-6: interleukin-6 (IL-6); BALF: bronchoalveolar lavage fluid; PGT: Pyunkangtang extract; CS: the mixture of cigarette smoke extract and sulfur dioxide. Concentration units are $\mathrm{mg} / \mathrm{kg}$.

$\mathrm{a}$; significantly different from control $(\mathrm{p}<0.05)$.

$\mathrm{b}$; significantly different from the mixture of cigarette smoke extract and sulfur dioxide alone $(\mathrm{p}<0.05)$.

orally-administered PGT inhibited the increase in TNF- $\alpha$ in BALF. The amount of TNF- $\alpha$ in the BALF samples were $100 \pm 28 \%, 1106 \pm 213 \%, 760 \pm 161 \%, 551 \pm 164 \%$, $414 \pm 157 \%$ and $374 \pm 99 \%$ for the control, CSE plus $\mathrm{SO}_{2}$ only, CSE plus $\mathrm{SO}_{2}$ - PGT $157 \mathrm{mg} / \mathrm{kg}$, CSE plus $\mathrm{SO}_{2}-$ PGT $314 \mathrm{mg} / \mathrm{kg}$, CSE plus $\mathrm{SO}_{2}$ - PGT $785 \mathrm{mg} / \mathrm{kg}$, and CSE plus $\mathrm{SO}_{2}$ - dexamethasone $0.5 \mathrm{mg} / \mathrm{kg}$ groups, respectively. A positive control, dexamethasone, inhibited TNF$\alpha$ secretion in BALF, due to its anti-inflammatory effects. Moreover, as shown in Fig. 6, exposure of rats to CSE plus $\mathrm{SO}_{2}$ for 3 weeks resulted in a significant increase in the level of IL-6, another proinflammatory cytokine, compared with that observed for the control group. However, orally-administered PGT inhibited the increase in IL- 6 in BALF. The amount of IL- 6 in the BALF samples was $100 \pm 19 \%, 366 \pm 47 \%, 222 \pm 30 \%, 219 \pm$ $42 \%, 106 \pm 22 \%$ and $113 \pm 15 \%$ for the control, CSE plus $\mathrm{SO}_{2}$ only, CSE plus $\mathrm{SO}_{2}$ - PGT $157 \mathrm{mg} / \mathrm{kg}$, CSE plus $\mathrm{SO}_{2}$ PGT $314 \mathrm{mg} / \mathrm{kg}$, CSE plus $\mathrm{SO}_{2}$ - PGT $785 \mathrm{mg} / \mathrm{kg}$, and CSE plus $\mathrm{SO}_{2}$ - dexamethasone $0.5 \mathrm{mg} / \mathrm{kg}$ groups, respectively. A positive control, dexamethasone, significantly inhibited IL-6 secretion in BALF, due to its antiinflammatory effects. These results suggest that PGT might control the production and secretion of inflammation- 
related cytokines, such as IL- 6 and TNF- $\alpha$, in COPD.

Taken together, these results can support the traditional use of PGT as an herbal remedy for treating several pulmonary inflammatory diseases including COPD. The underlying mechanism of actions of PGT on the inflammatory aspects of COPD is not clear at present, although we are currently taking a close look at whether PGT functions as a potential regulator of the NF- $\kappa B$ signaling pathway in human airway epithelial cells. We suggest it is valuable to find traditional herbal medicine and related natural products that have specific regulatory effects on COPD - in view of both basic and clinical sciences - and the results of the present study strongly suggest that PGT may be a potential therapeutic agent for COPD, although further studies are required to verify these findings.

\section{Acknowledgements}

This research was supported by a grant from Pyunkang Medical Foundation in 2017.

\section{References}

(1) Pauwels, R. A.; Rabe, K. F. Lancet. 2004, 364, 613-620.

(2) Mannino, D. M.; Buist, A. S. Lancet. 2007, 370, 765-773.

(3) Ramos, F. L.; Krahnke, J. S.; Kim, V. Int. J. Chron. Obstruct. Pulmon. Dis. 2014, 9, 139-150.

(4) Halbert, R. J.; Natoli, J. L.; Gano, A.; Badamgarav, E.; Buist, A. S.; Mannino, D. M. Eur. Respir. J. 2006, 28, 523-532.

(5) Stang, P.; Lydick, E.; Silberman, C.; Kempel, A.; Keating, E. T. Chest. 2000, 117, 354S-359S.

(6) Harber, P.; Tashkin, D. P.; Simmons, M.; Crawford, L.; Hnizdo, E.; Connett, J.; Lung Health Study Group. Am. J. Respir. Crit. Care Med. 2007, 176, 994-1000.

(7) Calverley, P. M.; Walker; P. Lancet. 2003, 362, 1053-1061.

(8) Corrigan, C. J.; Kay, A. B. Am. Rev. Respir. Dis. 1991, 143, $1165-$ 1168.
(9) Antoniu, S. A. Int. J. Chron. Obstruct. Pulmon. Dis. 2011, 6, 147155

(10) Siafakas, N. M.; Vermeire, P.; Pride, N. B.; Paoletti, P.; Gibson, J.; Howard, P.; Yernault, J. C.; Decrame, M.; Higenbottam, T.; Postma, D. S.; Rees, J. Eur. Respir. J. 1995, 8, 1398-1420.

(11) George, J.; Loannides-Demos, L. L.; Santamaria, N. M.; Kong, D. C.; Stewart, K. Med. J. Aust. 2004, 181, 248-251.

(12) Shinozuka, N.; Tatsumi, K.; Nakamura, A.; Terada, J.; Kuriyama, T. J. Am. Geriatr. Soc. 2007, 55, 313-314.

(13) Seo, H. S.; Lee, H. J.; Lee, C. J. J. Tradit. Chin. Med. 2016, 36, 663-670.

(14) Churg, A.; Cosio, M.; Wright, J. L. Am. J. Physiol. Lung Cell Mol. Physiol. 2008, 294, L612-L631.

(15) Cuzić, S.; Bosnar, M.; Kramarić, M. D.; Ferencić, Z.; Marković, D.; Glojnarić, I.; Eraković Haber, V. Toxicol. Pathol, 2012, 40, 1169-1187.

(16) O’Donnell, R. A.; Peebles, C.; Ward, J. A.; Daraker, A.; Angco, G.; Broberg, P.; Pierrou, S.; Lund, J.; Holgate, S. T.; Davies, D. E.; Delany, D. J.; Wilson, S. J.; Djukanovic, R. Thorax. 2004, 59, 837-842.

(17) Talhout, R.; Schulz, T.; Florek, E.; van Benthem, J.; Wester, P.; Opperhuizen, A. Int. J. Environ. Res. Public Health 2011, 8, 613-628.

(18) Husgafvel-Pursiainen, K. Mutat. Res. 2004, 567, 427-445.

(19) Su, Y.; Han, W.; Giraldo, C.; De Li, Y.; Block, E. R. Am. J. Respir. Cell Mol Biol. 1998, 19, 819-825.

(20) Evans, C. M.; Koo, J. S. Pharmacol. Ther. 2009, 121, 332-348.

(21) Rogers, D. F.; Barnes, P. J. Ann. Med. 2006, 38, 116-125.

(22) Kim, K. D.; Lee, H. J.; Lim, S. P.; Sikder, A.; Lee, S. Y.; Lee, C. J. Phytother Res. 2012, 26, 1301-1307.

(23) Hurst, J. R.; Donaldson, G. C.; Perera, W. R.; Wilkinson, T. M.; Bilello, J. A.; Hagan, G. W.; Vessey, R. S.; Wedzicha, J. A. Am. J. Respir. Crit. Care Med. 2006, 174, 867-874.

(24) Bradford, E.; Jacobson, S.; Varasteh, J. Comellas, A. P.; Woodruff, P.; O'Neal, W.; DeMeo, D. L.; Li, X.; Kim, V.; Cho, M.; Castaldi, P. J.; Hersh, C.; Silverman, E. K.; Crapo, J. D.; Kechris, K.; Bowler, R. P. Respir. Res. 2017, 18, 180.

(25) Pant, S.; Walters, E. H.; Griffiths, A.; Wood-Baker, R.; Johns, D. P.; Reid, D. W. Respirology. 2009, 14, 495-503.

(26) Lin, X.; Fan, Y.; Wang, X.; Chi, M.; Li, X.; Zhang, X.; Sun, D. Am. J. Med. Sci. 2017, 354, 388-394.
Received October 3, 2018

Revised December 9, 2018 Accepted December 9, 2018 